de ser de dos baras y / media de ancho y dos baras de Alto. En Prezio de mil $\mathrm{R}^{\mathrm{s}}$ de / V, ${ }^{\text {on }}$ Por cuya Causa el dho Liz ${ }^{\text {do }}$ Alonso Cano se obliga de / hazer El dho cuadro En la forma Referida y Entregarlo En / esta q $^{\text {te }}$ En Casa y poder del dho Blas López En todo El mes / de otubre (sic) que viene de este . $^{\text {te }}$ año Por q $^{\text {to. }}$ le a dado y Pagado / los dhos mil $\mathrm{R}^{\mathrm{s}}$ de vellón En [tachado: dinero de Contado de] dife- / rentes alajas y estampas. y mediante ellas sse dá Por en- / tregado de los dhos mil R ${ }^{\text {s }}$ Por haberlas Recivido a ssu sa- / tisfaz ${ }^{\text {on }}$ y Renunzia la excepcion y leyes de la Entrega y Prue- / ba del Recivo por no ser de $q^{\text {te }}$ y si Pasare El dho Mes de otu/ bre (sic) sin haberle Entregado el dho quadro Consiente ser apre- / miado al Entrego de lo Ex..$^{\text {do }}$ Por los dhos mil Rs a ele- / zion del dho Blas López En Virtud desta escritura sin / otro Recaudo alguno y siendo nezesario salir desta $\mathrm{q}^{\text {te }}$ / a la dha $\mathrm{Ex}^{\text {on }}$ y Cobranza Consiente que a ssu costa se pueda / Inbiar (sic) Persona dondequiera que estubiere o se allaren bienes / suyos Con quinientos mrs de salario En Cada un día de los / que se oCupare En la yda estada y buelta asta la Real / y efetiba (sic) Paga y por lo que ynPortaron los salarios / se le a de Poder hazer la mesma Ex ${ }^{\text {on }}$ que Por El prin // zipal y Renunziala Ultima Premática (sic) que los pro- / bó En los Contratos y Para Cumplirlo ansi obliga su / Persona y Vienes espirituales y tenporales avidos y por / haver y Para que conpelan doy Poder a todos los jue- / zes y justizias que de sus causas Puedan y deban conozer / de qualesquier Partes que sean a quién se somete y En es- / pecial al fuero y jurisdizión del Il, ${ }^{\text {mo }}$ monseñor nun- / cio de su santidad que Reside En esta q $q^{\text {te }}$ y lo Recive por / sentenzia Pasada En Cosa juzgada Renuncia su fuero / las demás leyes de su fabor la general y derechos / della y ansi lo dijo y otorgó ante mi el s. ${ }^{\text {no }}$ siendo testi- / gos don Thomás de Almansa y Juan Ruiz Residentes / En esta q ${ }^{\text {te }}$ que juraron a dios y a una Cruz conozer al otor- / gante y ser El mesmo aquí Contenido sin fraude ni en- / gaño y ansi mesmo fue testigo y Juan Albarez Residente / En esta $\mathrm{q}^{\text {te }}$ firmolo El otorgante y Un testigo de Conozim ${ }^{\text {to }} . /$

Alonso Cano

$\mathrm{tt}^{\mathrm{o}} . \mathrm{d}^{\mathrm{o}}$ Thomas de Almansa

y Laplaza

Ante mi

Pedro de Viana y Morales.

FERNANDO LÓPEZ SÁNCHEZ

\title{
NOTICIAS SOBRE UNA OBRA DEL ESCULTOR JUAN DE LEÓN EN ALCALÁ DE HENARES (1760-61)
}

La trayectoria vital y profesional de Juan de León no es demasiado conocida, cosa que en los últimos tiempos se ha venido a matizar. Fue originario de Aragón, concretamente de la localidad turolense de Bañón, donde nació y fue bautizado el 11 de junio de 1712. Trasladado a Madrid y activo en la Villa y Corte como escultor desde, al menos, 1743 — año de su primer matrimonio-, con residencia en la parroquia de S. Sebastián de la Corte en 1748, murió el 20 de mayo de 1767, habiendo hecho Declaración de Pobre, y habiéndose casado por segunda vez ${ }^{1}$.

Como ha señalado María Luisa Tárraga, fue en la Corte un escultor muy apreciado en su tiempo. Se le conoce sobre todo por su participación en la elaboración de los sepulcros de la reina Bárbara de Braganza y de su esposo el rey Fernando VI en las Salesas Reales, aunque realizó otras muchas obras escultóricas del entorno artístico cortesano ${ }^{2}$. Trabajó en el Real Sitio de Aranjuez, al menos en alguna ocasión como artífice de chimeneas (1747-48) ${ }^{3}$. Sobresale en su

${ }^{\prime}$ M. L. Tárraga Baldó, «Noticias biográficas de un escultor del siglo xviII: Juan de León», Archivo Español de Arte, 277, 1997, pp. 80-87.

${ }^{2}$ A. Ponz, Viage de España, Madrid, Vda. de Ibarra, 1793, V, p. 256; E. Serrano Fatigati, «Escultura en Madrid desde mediados del siglo XVI hasta nuestros días», Boletín de la Sociedad Española de Excursiones, XVIII, 1910, p. 70; Conde de Polentinos, «El Monasterio de la Visitación de Madrid (Salesas Reales)», Bol. Soc. Esp. Exc., XXIV, 1916, p. 281; Ceán Bermúdez, J. A. Diccionario histórico de los más ilustres profesores de las Bellas Artes en España, Madrid, Viuda de Ibarra, 1800, III, p. 10; E. Tormo y Monzó, Las iglesias del antiguo Madrid, Madrid, 1927; F. J. Portela Sandoval, La escultura en tiempos de Carlos III, Madrid, 1989.

${ }^{3}$ M. L. Tárraga Baldó, Art. cit., pp. 83 y 86. 
actividad la factura de diversas estatuas de la gran serie de los reyes de España que iban a colocarse en la balaustrada superior y otras zonas del Palacio Real. En abril de 1750 cobró 11.000 reales por cada una de las esculturas de los reyes Recaredo, Chindasvinto, Isabel la Católica y Fernando el Católico. Del piso principal, realizadas entre 1751 y 1753, ejecutó la de Jaime I el Conquistador, desbastada por Pedro Martiniego, bajo las órdenes de Felipe de Castro - escultor que propuso a Juan de León para el trabajo - recibiendo por ello 14.000 reales ${ }^{4}$.

En Madrid realizó también las esculturas que decoraban la desaparecida fuente de la Plaza de la Villa diseñada por Juan Bautista Sachetti, que contrató en mayo de 1754 y se inauguró cinco meses después ${ }^{5}$. Sustituyó, junto a otros escultores españoles, a Felipe de Castro en la decoración de la Capilla de Palacio (1754), realizando obra de estuco ${ }^{6}$; a propuesta de Castro realizó un relieve de mármol del Martirio de S. Lorenzo - que se conserva en la Real Academia de Bellas Artes de S. Fernando-y otro, inacabado, del Tercer Concilio de Toledo, para las sobrepuertas de la Galería del Palacio (1758) ${ }^{7}$. Incluso retasó, junto con Roberto Michel, el relieve del que fue autor Francisco Devoge, ante la disparidad de criterios al respecto de Olivieri y Castro. Dentro de la tradición imaginera más tradicional debe incluirse la estatua de S. Nicolás que hizo para la antigua iglesia de Santa María de Atocha ${ }^{8}$. En tanto que escultor cortesano, participó en la decoración de la Santa Capilla de la Basílica del Pilar de Zaragoza. Su labor se centró en cinco medallones de estuco con angelotes músicos para los cascarones $(1762-65)^{9}$.

El trabajo que realizó para Alcalá, y que ahora damos a conocer, se le encargó en 1760 por parte del Colegio Mayor de S. Ildefonso, y consistió en la ejecución de una estatua de madera estofada, dorada y pintada con la representación de Santo Tomás de Villanueva vestido de arzobispo para la iglesia del Colegio.

El Colegio Mayor de Alcalá contaba, desde 1654, con una escultura del santo agustino, arzobispo de Valencia y antiguo colegial, graduado y docente complutense, también de madera pintada y estofada, de cuerpo entero y que lo representaba con el manto de colegial de S. Ildefonso. Esta imagen se había encargado con motivo de los acontecimientos relacionados con el proceso de canonización del santo - beato desde 1618 - , que se culminaría en 1658, cuando el Colegio y Universidad de Alcalá conseguía licencia para rezar, decir misa y celebrar fiesta en su honor gracias a las gestiones de los agentes que la institución académica tenía en la Curia Romana. Su función original fue la de servir de paso procesional en las celebraciones que la Universidad organizó en adelante para homenajear a su ilustre colegial, con su punto culminante en las fiestas por su exitosa canonización. La escultura, sin embargo, pasaría, tras las actuaciones de otro proceso de canonización, el del Cardenal Cisneros (1668), a ocupar un retablo de madera dorada que se contrató en 1626 para albergar los restos mortales del gran prelado toledano y fundador de la Universidad de Alcalá. Las autoridades canónicas señalaron lo contrario a la nor-

\footnotetext{
${ }^{4}$ F. J. de la Plaza Santiago, Investigaciones sobre el Palacio Real Nuevo de Madrid, Valladolid, 1975, pp.197-198 y 213221 .

${ }^{5}$ Conde de Polentinos, «Datos históricos sobre la Casa Ayuntamiento de Madrid», Bol. Soc. Esp. Exc., XX, 1912, p. 251; F. J. de la Plaza Santiago, Op. cit., p. 28.

${ }^{6}$ F. J. de la Plaza Santiago, Op. cit., pp. 148-149; M. L. Tárraga Baldó, Giovan Domenico Olivieri y el taller de escultura del Palacio Real, Madrid, 1992, III, pp. 351-353.

${ }^{7}$ M. Lorente Junquera, «Los relieves marmóreos del Palacio Real de Madrid», Arte Español, XX, 1954, pp. 61, 64 y 71; F. J. de la Plaza Santiago, Op. cit., pp. 183-184.

${ }^{8}$ A. Ponz, Op. cit., V, p. 23; E. Tormo y Monzó, Op. cit., 1927 (reedición 1979, p. 220). Según Ceán (Op. cit.) realizó otras obras similares para varios templos de Madrid.

${ }^{9}$ A. Ponz, Op. cit., XV, pp. 10-11. También M. V. Aramburu de la Cruz, Historia Chronologica de la Santa, Angélica y Apostolica Capilla de Ntra. Sra. del Pilar, Zaragoza, Imp. del Rey, 1766, p. 109; B. Boloqui Larraya, Escultura zaragozana en la época de los Ramírez, 1710-1780, Granada, 1983, pp. 177-178; R. Usón García, La intervención de Ventura Rodríguez en el Pilar. La Santa Capilla generatriz de un sueño arquitectónico, Zaragoza, 1990, pp. 95-97.
}

AEA, LXXVII, 2004, 305, pp. 75 a 97 
mativa sobre beatificaciones de la preeminente situación de los restos de Cisneros en la iglesia de S. Ildefonso y ordenaron que en su lugar se situase la escultura de Santo Tomás, y que el retablo pasase a considerarse altar dedicado al antiguo colegial, agustino y arzobispo de Valencia ${ }^{10}$.

Pasados los años, el 5 de septiembre de 1760, el penitenciario del Colegio Mayor de S. Ildefonso, José Otaola, hacía saber al rector y los consiliarios, mediante un informe que les presentó,quelaesculturadelSantoestaba «mиy quebrantada, y quasi hecha pedazos», por lo que debía sustituirse por otra, y el altar de Santo Tomás muy afectado por la humedad y la suciedad, lo que hacía indecorosa su vista y poco menos que imposible que en él se dijese misa, por lo que aconsejaba que se cambiase su ubicación, además de otras consideraciones menores. El rector y los consiliarios aceptaron los consejos del informe y encomendaron al capellán mayor del Colegio, entre otras cosas, el encargo de una nueva escultura del santo colegial, dejando a su criterio el traslado del altar que, por lo que sabemos, no debió materializarse finalmente ${ }^{11}$. De esa forma, el 28 deseptiembre,sepagabanauncolegialllamado Villanueva 855 reales de vellón para que los entregase al escultor vecino de Madrid D. Juan de León «por quenta del importe de una efigie del $S^{\text {or }}$. $S^{\text {to }}$. Thomàs de villanueva» que se había mandadohacerparalaiglesiadeS.Ildefonso ${ }^{12}$. El6deabrilde 1761 se libraron al escultorotros 1.235 reales de vellón, y según el registro del libramiento 1.125 de ellos correspondían a lo que se le faltaba por pagar de los 33 doblones en los que se había concertado la escultura, mientras que los 110 restantes lo eran por el

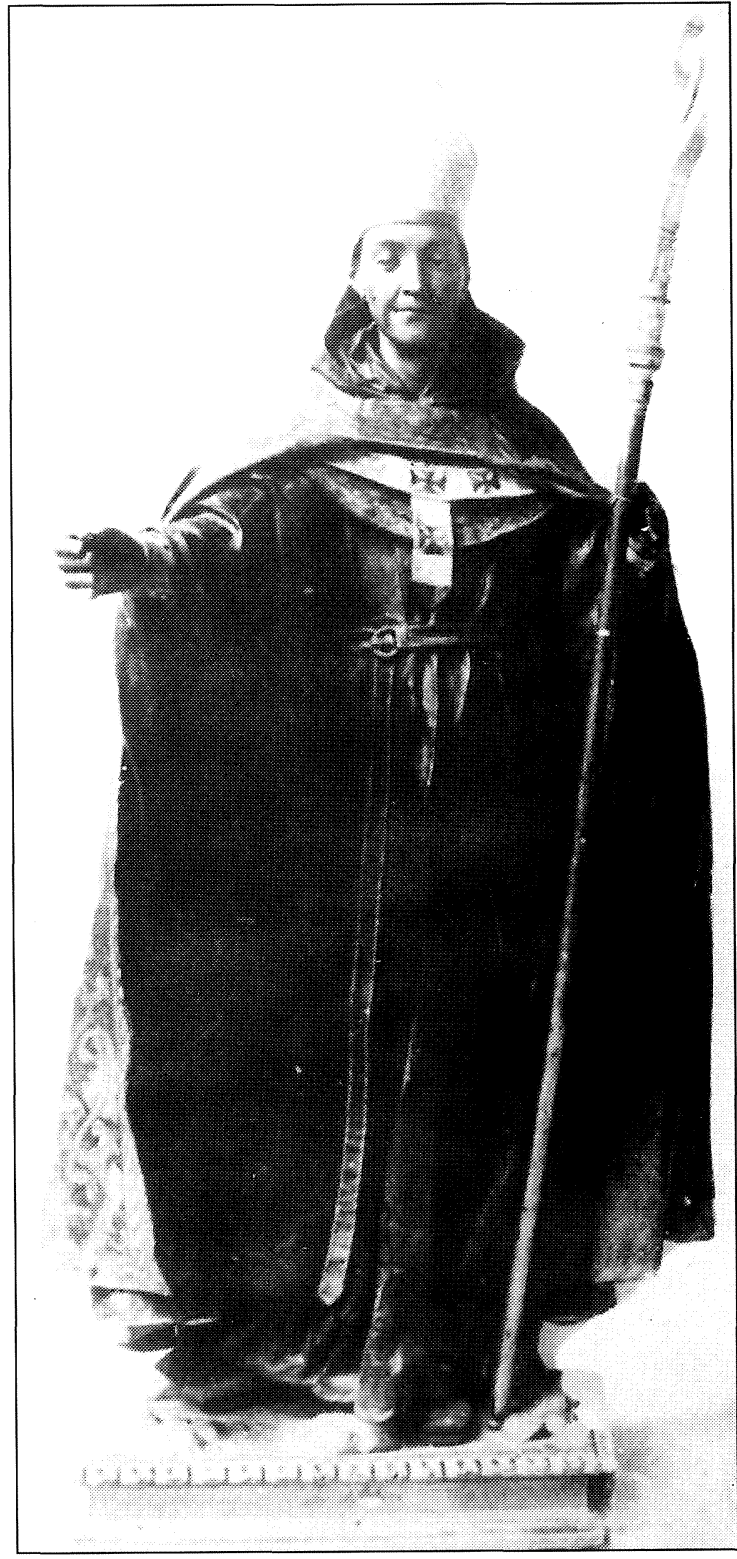

Juan de León: Santo Tomás de Villanueva. Fotografía antigua de la escultura que se encontraba en la iglesia del Colegio Mayor de San Ildefonso de Alcalá de Henares. transporte de Madrid a Alcalá ${ }^{13}$. En este sentido, se abonaron al vecino de Alcalá José García, el 12 de junio siguiente, 80 reales de vellón

\footnotetext{
${ }^{10}$ Véase, sobre este tema: R. González Ramos, El mecenazgo artístico de la Universidad de Alcalá de Henares (siglos XVI-XIX): inventario crítico de su patrimonio pictórico y escultórico, Tesis Doctoral inédita, Madrid, Universidad Autónoma, 2002, pp. 623 y ss.

$"$ Archivo Histórico Nacional (A.H.N.), sección Universidades, Libro 697, fols. $179 \mathrm{v}^{\mathrm{o}}-181 \mathrm{r}^{\circ}$, libros de actas de la capilla de rector y consiliarios.

${ }^{12}$ A.H.N., Universidades, Libro 904, fol. 157 v , libro de registro de libramientos. La orden de pago a Juan de León, escultor vecino de Madrid, de los 855 reales por cuenta de los 33 doblones en que se había ajustado la «efigie», firmada el 26 de septiembre de 1760, en ibid., Libro 153, fol. $352 \mathrm{r}^{\circ}$, libro de registro de escrituras otorgadas ante los escribanos contadores.

${ }^{13}$ A.H.N., Universidades, Libro 904, fol. $159 \mathrm{v}^{\circ}$, libro de registro de libramientos.
}

AEA, LXXVII, 2004, 305, pp. 75 a 97 
por «la conducción de la efigie nueva de s ${ }^{\text {to }}$. Thomàs de Villanueva desde Madrd, y trahèr (sic), yllevaralescultor $q^{e}$. la hizo, y su oficial ${ }^{14}{ }^{14}$. La estancia de Juan de León en Alcaládebió relacionarse con el último pago que recibió y con la presentación de su trabajo a los clientes, puesto que su obra se realizó en la Corte, y no creemos que necesitase acudir al Colegio para tomar medidas o contratar su ejecución.

Sabemos que la escultura con la representación del santo, vestido de arzobispo y religioso, se conservó en S. Ildefonso hasta, al menos, 1799, según indican sus inventarios de bienes ${ }^{15}$, y que allí permaneció hasta 1936. De esa escultura, cuyo paradero se desconoce, conservamos una fotografía antigua que aparece reproducida en un libro de Carolina Lorente ${ }^{16}$. Aunque no es de excesiva calidad, nos permite conocer bastante bien cómo era esa pieza y comprobar el barroquismo dieciochesco de su estilo, que destaca en la ampulosidad de las telas y riqueza del estofado.

A pesar de que la Universidad de Alcalá desapareció en 1836-37, y muchas de las obras de arte que aún conservaba fueron trasladadas a la de Madrid, la escultura de Santo Tomás no llegó a trasladarse nunca a la capital, y permaneció en Alcalá hasta su desaparición, cambiando de lugar, sin salir nunca de la iglesia de S. Ildefonso. En 1882 se publicaba la guía turística de Alcalá de Henares Guía del viajero en Alcalá de Henares, del canónigo de la Magistral D. Liborio Acosta de la Torre ${ }^{17}$. Al hablar sobre el interior de la iglesia del antiguo Colegio Mayor, tras señalar que todas las obras de arte que no se trasladaron a Madrid, a excepción de sepulcro cisneriano y su reja - por entonces en la Magistral alcalaína-, se habían perdido, indica en una nota: «En esta Iglesia existen [...] $2^{\circ}$. Un Sto. Tomas de Villanueva, propiedad de la Universidad, y que estuvo en la habitación que ocupó el Santo cuando estudiaba» ${ }^{18}$. Aunque las tradiciones sin fundamento le hacían afirmar que la escultura había estado en la famosa celda-oratorio del santo que había en el Colegio — sabemos que no es verdad-, lo cierto es que nos da la noticia del mantenimiento hacia 1882 de la obra en la iglesia, señalando que pertenecía a la Universidad de Madrid, que la tendría allí en depósito. No sabemos qué fue del retablo que la albergó. Lo que podemos afirmar es que fotografías de finales del siglo XIX o principios del siguiente continúan registrando la escultura, si bien situada en la nave de la iglesia, en el lado de la Epístola, sobre una peana de lo más rústica. Las guías de Alcalá de Henares de D. Elías Tormo y Heliodoro Castro, de hacia 1929, se hacen eco de la existencia de la estatua de madera policromada ${ }^{19}$. La efigie siguió en su lugar hasta la Guerra Civil de 1936, cuando se pierde su pista, seguramente destruida, pero se conserva de ese momento casi el único y mejor testimonio gráfico de su aspecto, la fotografía en blanco y negro a la que ya nos habíamos referido y que aportamos.

RoBerto GonZÁlez RAMOS

${ }^{14} \mathrm{Ibid}$., fol. $160 \mathrm{r}^{\mathrm{0}}$. El pago por la escultura se refleja en los libros de mayordomía y contaduría en: ibid., Libro 360, fol. $112 \mathrm{r}^{\circ}$.

${ }^{15}$ Ibid., Libro 677, fols. $50 \mathrm{v}^{\circ}, 59 \mathrm{r}^{\circ}, 68$ ro 81 ro $91 \mathrm{v}^{\circ}$ y $98 \mathrm{v}^{\circ}$ (inventarios de 1761,1769, 1778, 1786, 1793 y 1796 respectivamente), Libro 1080, fol. $201 \mathrm{r}^{\circ}$ (inventario de 1777), Legajo 551, fol. $15 \mathrm{v}^{\circ}$ (inventario de 1788), y Libro 415, fol. $32 \mathrm{v}^{\circ}$ (inventario de 1799).

${ }^{16}$ C. Lorente Villalba, Tomás García Martínez, Santo Tomás de Villanueva, Alcalá de Henares, 1986. También puede verse, con menor grado de detalle, en una de las fotografías que existen del interior de la iglesia, cuando ya no tenía nada que ver con la Universidad, anteriores a la Guerra Civil de 1936.

${ }^{17}$ L. Acosta de la Torre, L. Guía del viajero en Alcalá de Henares, Alcalá de Henares, 1882.

${ }^{18}$ Op. cit., p. 135, nota.

${ }^{19}$ H. Castro, Guía ilustrada histórico-descriptiva de Alcalá de Henares, Alcalá de Henares, 1929, p. 57; E. Tormo y Monzó, Alcalá de Henares, Madrid, 1929 (?), p. 31

AEA, LXXVII, 2004, 305, pp. 75 a 97 